\title{
Khipu Archives: Duplicate Accounts and Identity Labels in the Inka Knotted String Records
}

\section{Citation}

Urton, Gary. 2005. "Khipu Archives: Duplicate Accounts and Identity Labels in the Inka Knotted String Records." Latin American Antiquity 16 (02) (June): 147-167. doi:10.2307/30042809.

\section{Published Version}

doi:10.2307/30042809

\section{Permanent link}

http://nrs.harvard.edu/urn-3:HUL.InstRepos:33702053

\section{Terms of Use}

This article was downloaded from Harvard University's DASH repository, and is made available under the terms and conditions applicable to Other Posted Material, as set forth at http:// nrs.harvard.edu/urn-3:HUL.InstRepos:dash.current.terms-of-use\#LAA

\section{Share Your Story}

The Harvard community has made this article openly available.

Please share how this access benefits you. Submit a story.

Accessibility 


\title{
KHIPU ARCHIVES: DUPLICATE ACCOUNTS AND IDENTITY LABELS IN THE INKA KNOTTED STRING RECORDS
}

\author{
Gary Urton
}

\begin{abstract}
Accounts from the Spanish chronicles regarding Inka record-keeping practices by means of the knotted string devices called khipu ("knot") indicate that these accounts were compiled in a system of "checks and balances." Each community in the empire had a minimum of four khipu accountants, all of whom are said by the chronicler Garcilaso de la Vega to have kept the same records. This study examines several examples of matching khipu accounts identified among sets of two or three khipu. The identification of matching khipu accounts has been facilitated by the recent development of a khipu database at Harvard University. It is argued that certain three-term numerical sequences recorded in one set of three matching khipu from Chachapoyas, northern Peru, represent a type of numerical signifier that may have served as identity labels of the information recorded in this set of khipu. The long-range objective of this research is to investigate the information recorded on khipu from various provenience zones around the former Inka Empire that may represent the remains of khipu archives.

Relatos en las crónicas españolas relativas a la práctica Inka de mantenimiento de registros por medio de dispositivos de cordeles anudados denominados khipu ("nudo") indican que estos eran recopilados dentro de un sistema de "controles y balances." Cada comunidad en el imperio poseía un mínimo de cuatro "contadores" o registradores de khipu, todos los cuales, según relata cronista Garcilaso de la Vega, llevaban y mantenían los mismos registros. Este estudio examina diversos ejemplos afines y de concordancia compartida, identificados entre conjuntos de dos o tres ejemplares de khipu. La identificación de registros de khipu con afinidad y concordancia ha sido considerablemente facilitada por el reciente desarrollo de una base de datos en la Universidad de Harvard. Se plantea que ciertas secuencias numéricas de tres elementos registradas en un conjunto de tres khipus afines de Chachapoyas en el norte del Perú, representan un tipo de significador numérico que podrían haber fungido o desempeñado como rótulos de identidad de la información registrada en este conjunto de khipus. El objetivo a largo plazo de esta investigación es la de averiguar la información registrada en ejemplares de khipu de diversas zonas del antiguo Imperio Inka, que pudiesen representar los remanentes de archivos de khipu.
\end{abstract}

$\mathrm{O}$ ne intriguing claim made by the chronicler of Inka life, Garcilaso de la Vega, regarding Inka record keeping is that the knottedstring devices known as khipu ("knot") were used in a system of checks and balances. This system is explained by Garcilaso as follows:

Although the quipucamayus [khipumakers/keepers] were as accurate and honest as we have said, their number in each village was in proportion to its population, and however small, it had at least four and so upwards to twenty or thirty. They all kept the same records, and although one accountant or scribe was all that would have been necessary to keep them, the Incas preferred to have plenty in each village and for each sort of calculation, so as to avoid faults that might occur if there were few, saying that if there were a number of them, they would either all be at fault or none of them [1966 (1609):331; my emphasis].

How are we to understand the meaning of Garcilaso's claim? For instance, does his statement mean that the four to 30 (or more) khipu keepers in a given village kept exactly the same records, using the same recording principles and procedures? Who would have collated, compared, and (if necessary) corrected the various accounts? Was all the information recorded on each of these khipu duplicated exactly and completely on other khipu, or might any two related khipu have contained only

Gary Urton - Department of Anthropology, Peabody Museum 58B, 11 Divinity Avenue, Harvard University, Cambridge, MA 02138-2019 (gurton@fas.harvard.edu). 
partial or perhaps overlapping accounts? If we were to identify what we thought were matching khipu accounts, how could we be certain that this resulted from two different individuals recording the same information as opposed to one khipu keeper copying his own account, or even a student copying an account of a more experienced record keeper?

These are just a few of the many questions that arise from a consideration of Garcilaso's statements about Inka record-keeping practices. While students of the khipu have long been aware of the checks and balances aspect of Inka khipu record keeping, no one to date has paid much attention to this critical administrative practice. I will address this lacuna in khipu studies by considering several examples of khipu accounts that seem to contain if not the same, then very similar data, and that may, therefore, represent surviving examples of the administrative apparatus and practices attested to in Garcilaso's statement. In the course of this study, we may also be able for the first time to say something fairly concrete about the use of "identity labels" in khipu accounts. We will encounter such constructions in a set of three duplicate, or matching, khipu samples from Chachapoyas, northern Peru.

My interest in pursuing the topic of checks and balances in the Inka khipu arose from a rather surprising development in a project that I am directing at Harvard University, which is aimed at creating a searchable khipu database. ${ }^{1}$ This project, which is under the day-to-day direction of Carrie Brezine (a mathematician, weaver, and database manager), is aimed at producing a database that can be queried for patterns among numerous different khipu features, such as numbers, colors, and directional variations in the spin, ply, attachment, and knotting of strings. A query of some of the first khipu that were entered into the database-22 samples discovered at the Lake of the Condors site, in Chachapoyas, northern Peru-revealed an extremely interesting match of primarily numerical information among three different khipu. I will later present the details of this match. At the time of our discovery of khipu matches from Lake of the Condors, I was unaware of other examples of this phenomenon in the khipu corpus. However, I subsequently became aware of several additional matches, and my objective here is to describe and analyze the examples that are known to me at the present time. ${ }^{2}$ On the basis of these data and their analysis, I will reflect on how this material may relate to what Garcilaso had to say in the account cited earlier concerning the multiplicity of record keepers in Inka administration and what these practices suggest about the control and manipulation of information in the empire.

I should clarify that when I discuss "matching khipu," I am referring primarily to correspondences in the numerical information encoded (i.e., knotted) into the cords of two or three different khipu. As has been understood since the early years of the last century (Locke 1923), the majority of Inka khipu have knots tied into their strings in hierarchical tiers that represent increasingly higher powers in the Inka decimal system of accounting (Ascher and Ascher 1997; Urton 1997, 2003). In addition to such knot-based indicators of numerical values, however, there are several other means whereby the khipu keepers recorded other, or modifying, types of information. These additional sign features include color (both of camelid hair and of differently colored cotton), as well as several forms of variation and patterning of khipu construction features, such as material (primarily camelid or cotton) differences and directional variation in spinning, plying, knotting, and attaching khipu cords (see Conklin 2002; Urton 1994, 2003). We do not yet understand what specific meanings might have been attached to any one of these latter elements, nor of how they might, singly or in combination, have signed meanings or values in the khipu information system. ${ }^{3}$ Therefore, although I will occasionally discuss color similarities and differences, my primary — and certainly initial—focus here will be on the examination of numerical matches between khipu samples.

The larger objective of this study is to articulate and begin to develop an explicitly archival approach to the study of the Inka khipu. Such an approach, which was first (to my knowledge) proposed by the great Italian-Peruvian student of the khipu, Carlos Radicati di Primeglio (1949-50; see Urton 2005), ${ }^{4}$ would focus attention on bringing together for comparative analysis samples with common provenance, or ones that actually derive from the same archaeological context. The value of such an approach will be that it will (a) encourage crosscollection study of samples with common provenance in museums around the world, (b) encourage the collection of information from all khipu (pro- 
vided they are not too fragile for study) regardless of their incomplete or fragmentary nature, and (c) provide the comparative data essential to investigating, in an informed and critical manner, Inka record keeping and administrative procedures at local, regional, and state levels of organization. I will return to the general question of developing an archive-based program of khipu studies in the conclusions. We begin our study of khipu checks and balances by looking at several examples of pairs of matching khipu, all of which are from sites along the central and south coast of Peru.

\section{Pairs of Matching Khipu}

What appears to be a straightforward example of a correlation of information registered on two different khipu occurs in the collection of the American Museum of Natural History (AMNH) in New York. The provenance of these khipu was said to be near Callango, in the Ica Valley. The two samples in question, both made of cotton, bear the museum numbers $41.2 / 6702$ and $41.2 / 6703$. These khipu have been partially described, in tabular format, in Marcia and Robert Aschers's (1978) Code of the Quipu: Databook. ${ }^{5}$ In the Aschers's notational system, these two khipu are identified, respectively, as AS194 and AS195. ${ }^{6}$ I will use these latter designations in the following discussion.

Khipu AS194 bears two pendant strings, the first of which (P1) bears three subsidiaries. The first of the three subsidiaries (P1s1) itself bears two subsidiaries (P1s1s1/s2). The second pendant string (P2) of Khipu AS194, which is a blank (i.e., it does not carry any knots), is separated from P1 by 21 $\mathrm{cm}$. The color ${ }^{7}$ and number values of the pendants and subsidiaries on AS194 are shown in Figure 1a.

The other sample in this pair, Khipu AS195, contains only one pendant string (P1). However, P1 bears three subsidiaries, the first of which (P1s1) itself bears three subsidiaries (P1s1s1/s2/s3). The third subsidiary of P1 (= P1s3) is broken off from the pendant cord at $4 \mathrm{~cm}$. The colors and numerical values assigned by the Aschers to the strings composing AS195 are given in Figure 1b.

As we see in Figures 1a and b, the numerical values of knots on the pendants and subsidiaries of AS194 and 195 are almost identical. (All knots on these two khipu are tied as Z-knots). The major differences are in the absence of a third pendant, or subsidiary, valued " 4 " on AS194 (this value could have been registered on the now broken second subsidiary of P1), and several differences in string colors between the two khipu. This instance appears to be a fairly straightforward case of a body of information recorded on one khipu that is repeated on another. The fact that the color values associated with the series of numbers on these two khipu are not identical might indicate that the khipu keepers who constructed the two records had their individual color sign values for indicating some feature(s) of the identity of the numbers of objects, activities, etc., registered on their khipu.

Before going too far along the interpretive line for explaining color differences suggested above, however, we should recognize that these two samples might, in fact, have been constructed by the same person at two different times, or perhaps in relation to two different bodies of information. According to this alternative explanation, the same numbers and groupings of individuals (= the numbers recorded on the pendant strings) were identified in relation to different characteristics ( $=$ the string colors). Given the present state of knowledge of Inka record keeping by means of the khipu, we cannot say what the precise meaning of the color differences - or even the numerical similaritiesin these two samples was. Nonetheless, it seems a reasonable assumption that this first pair of "matched" khipu represents an expression of the system of checks and balances as described in the previously cited testimony from Garcilaso de la Vega.

The second example of matching khipu accounts comes from a pair of cotton khipu included in a group of eight samples acquired by the Museum für Völkerkunde, in Berlin, in 1904. The provenance of this set of eight khipu is given in museum records as between Ica and Pisco, on the south coast of Peru. ${ }^{8}$ The museum identifications and investigator numbers for the two samples are VA16138A (=AS159) and VA16145A (=AS173).

Khipu AS159 is composed of a total of 35 pendant strings. The first seven pendant strings (with any subsidiaries) are diagrammed in a schematic fashion in Figure 2a. AS173 is composed of a total of only 13 pendant strings. In Figure 2b, I provide a schematic diagram of the first eight pendant strings and subsidiaries of this sample. 


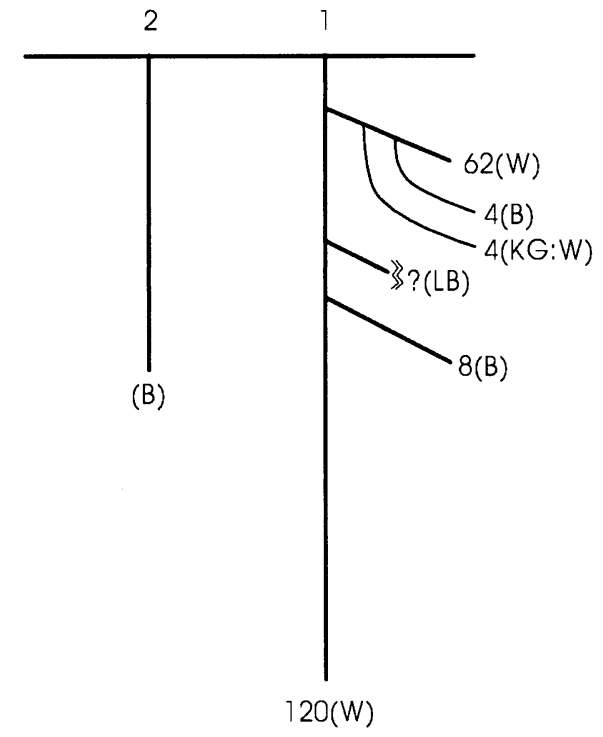

(a)-AS194

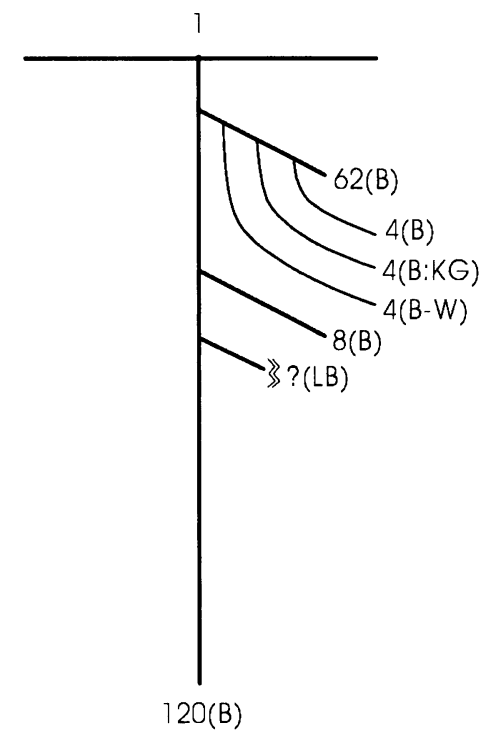

(b)-AS195

Figure 1. Khipu matching pair: AS194 and AS195.?

The seven pendant strings (P1-7) on AS159 are identical in terms of their numerical values and their pendant/subsidiary structure to seven pendant strings (P2-8) on AS173. The remaining five pendant strings (P9-13) of AS173 do not contain matches with any segment of the remaining 28 pendants (P8-35) on AS159. Thus, it is as though the first one-fifth (i.e., P1-7) of AS159 is replicated on the majority of AS173. Said another way, AS173 might have been the source of the information recorded in the first part of AS159. In this scenario, however, the remaining four-fifths of the data in AS159 is unaccounted for, at least with present information. This raises the question of whether or not there might be other khipu with IcaPisco provenance that recorded other segments of pendants on AS159, and even the remaining short, unmatched segment of AS173. We have not yet succeeded in identifying such samples from the data in our database.

The next example of matching khipu is another pair from the Museum für Völkerkunde in Berlin; these are samples VA16148 and VA47085, which bear (respectively) the Ascher investigator numbers AS 114 and AS123. This matching pair was identified in a search of the khipu entered into the Harvard Khipu Database. Khipu AS114 has a provenance between Ica and Pisco, while AS123 bears a provenance of Ica. These two samples are of notably different sizes: AS114 is composed of 339 pendant strings whereas AS123 bears only 70 strings. Both samples have numerous subsidiary cords on their pendants, although no subsidiaries are present within the two stretches of pendant strings examined here. The values of knots registered on the two segments of pendant cords are shown in Figure 3.

Although of very different sizes, the matching series of 10 pendant cords on these two samples are found at virtually the same locations on their respective khipu; that is, the set of 10 matching strings on AS1 14 is found on pendants 40-49, while the 10 strings on AS123 are located on pendants 41-50. Thus, there are 39 strings preceding and 290 strings following the segment from AS114 under discussion, and there are 40 strings preceding and 20 strings following the segment shown from AS123. This raises the question: How do the remainder of the pendant values on these two khipu relate to each other? From a careful comparison (see the Ascher tables for AS114 and AS123 at http://instruct1.cit.cornell.edu/research/quipuascher/), we find no additional segments that match (numerically) between these two khipu. 


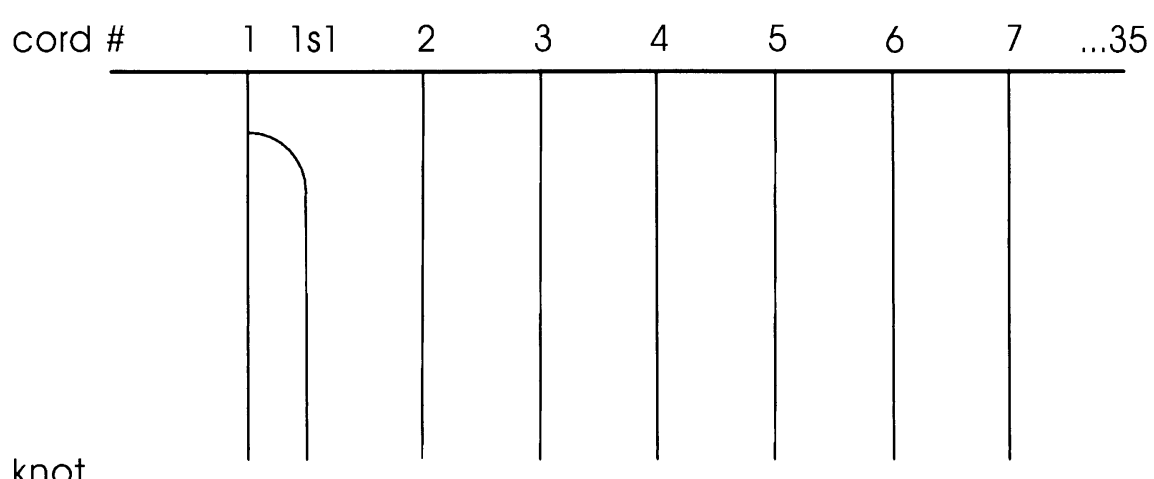

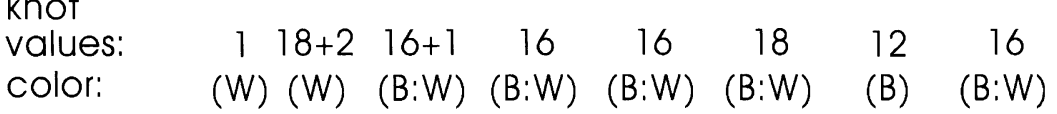

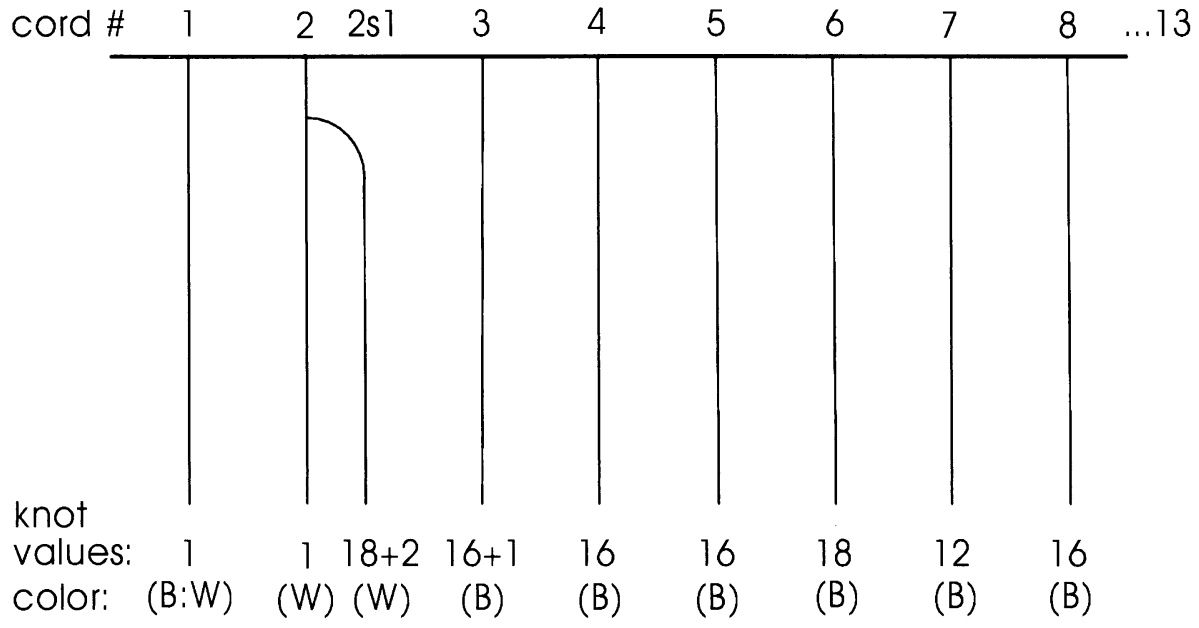

Figure 2. Khipu matching pair: a. AS159 (above) and b. AS173 (below). ${ }^{7}$

The main similarities between the two accounting contexts in which the number series defined above are located are that: (a) there is at least one null (i.e., zero valued) string before and after each of our matching segments; and (b) the pendant strings on which the respective 10-string segments are located on the two samples are all the same color, though the color differs slightly between the two series - that is, the 10 strings in AS114 are all colored grayish brown (HB), while those in AS123 are all grayish yellowish brown (EB)

My supposition is that these matching 10-string segments may represent "isolable" units within their respective khipu, suggesting that these segments could have been accounted for apart from the information on the neighboring strings of their respective host khipu. This implies that the matching segments may represent information that came from a common source. For example, these matching numerical data could have come from two different khipu keepers who were responsible for recording information on the same task or characteristic(s) of a single accounting group, such as the kin-based groups known as ayllus (see Salomon 2002). Alternatively, a section of one of these khipu (e.g., AS123) could have been the source for the account recorded in the comparable section on the other khipu (AS114). The fact that the remainder of the data recorded in the two accounts is different suggests that the khipu keepers who retained these records shared only this one accounting responsibility. 


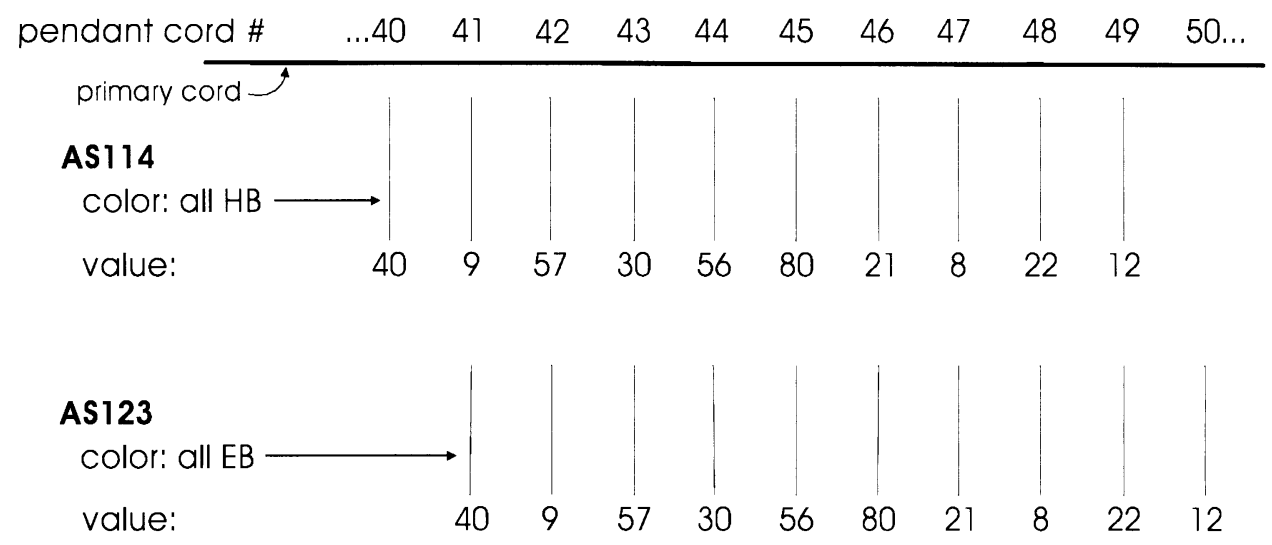

Figure 3. Khipu matching pair: AS114 and AS123. ${ }^{7}$

\section{Close Matches or Successive Accountings?}

We turn now to an example of matching khipu segments that occurs within one of the samples just discussed-Khipu AS114. Because AS114 contains a total of 339 pendant strings, it is impossible to represent in a diagram every string along with their numerical and color values. Nonetheless, it is important for gaining clarity on this complex khipu to illustrate in at least a schematic manner the type of comparative account keeping in this sample.

The illustration of selected strings from AS114 that I will analyze (see Figure 4) is arrived at in the following manner: If we were to fold Khipu AS1 14 into two equal parts, we would have one part composed of strings 1-169 and a second part composed of strings 170-339. I will refer to these half-khipu parts as (respectively) A and B. However, I must enter a caveat before examining several sets of paired values in the two halves of Khipu AS114. There are several segments in the paired halves of this khipu that contain strings with no knots; thus, these strings contain no numerical values. I will eliminate the segments of null valued strings in our analysis (and their illustration). The locations of the eliminated sections are indicated in Figure 5 by horizontal lines drawn across the columns of the paired sets of strings. The location and quantity of null valued strings within the six paired sets can be determined by looking at the breaks in the number sequences in the columns labeled "cord number" in the figure. These operations on AS114 produce 11 paired groups of strings. We will look specifically at the first six sets.
In analyzing the information in Figure 5, we see, first, that the color of paired strings in the two parts of the khipu are in most cases identical. As for the knot values on corresponding strings in Parts $A$ and $\mathrm{B}$, these are identical in some cases, close in others, and quite far apart in several cases. However, if one looks down the length of paired values in the six segments of AS114, Parts A and B, one will be struck both by the similarity in the overall pairing of magnitudes and colors registered in the two halves of this khipu.

The question that confronts us in viewing Figure 5 is what can this particular patterning have meant to the khipu keeper who was charged with keeping this account in the two halves of his khipu? This seems clearly not to have been an instance of two different khipu keepers at work on separate, related accounts, as in the situation described by Garcilaso cited earlier. Rather, this seems to be a record of a single accountant's detailing, in the two halves of his khipu, two different but similar accounting states or circumstances. For example, Khipu AS1 14 could be an account adjustment, perhaps resulting from recording information on the same topic at two different times. The most direct example would be drawn from a demographic context. For instance, one half (e.g., Part A) of Khipu AS114 might have been the census of the population living in some given region around presentday Ica at one point in time and the other half (Part B) could have been the record of the census of that same population made at another time.

Such a process of counting and recounting populations and recording the results in khipu described 


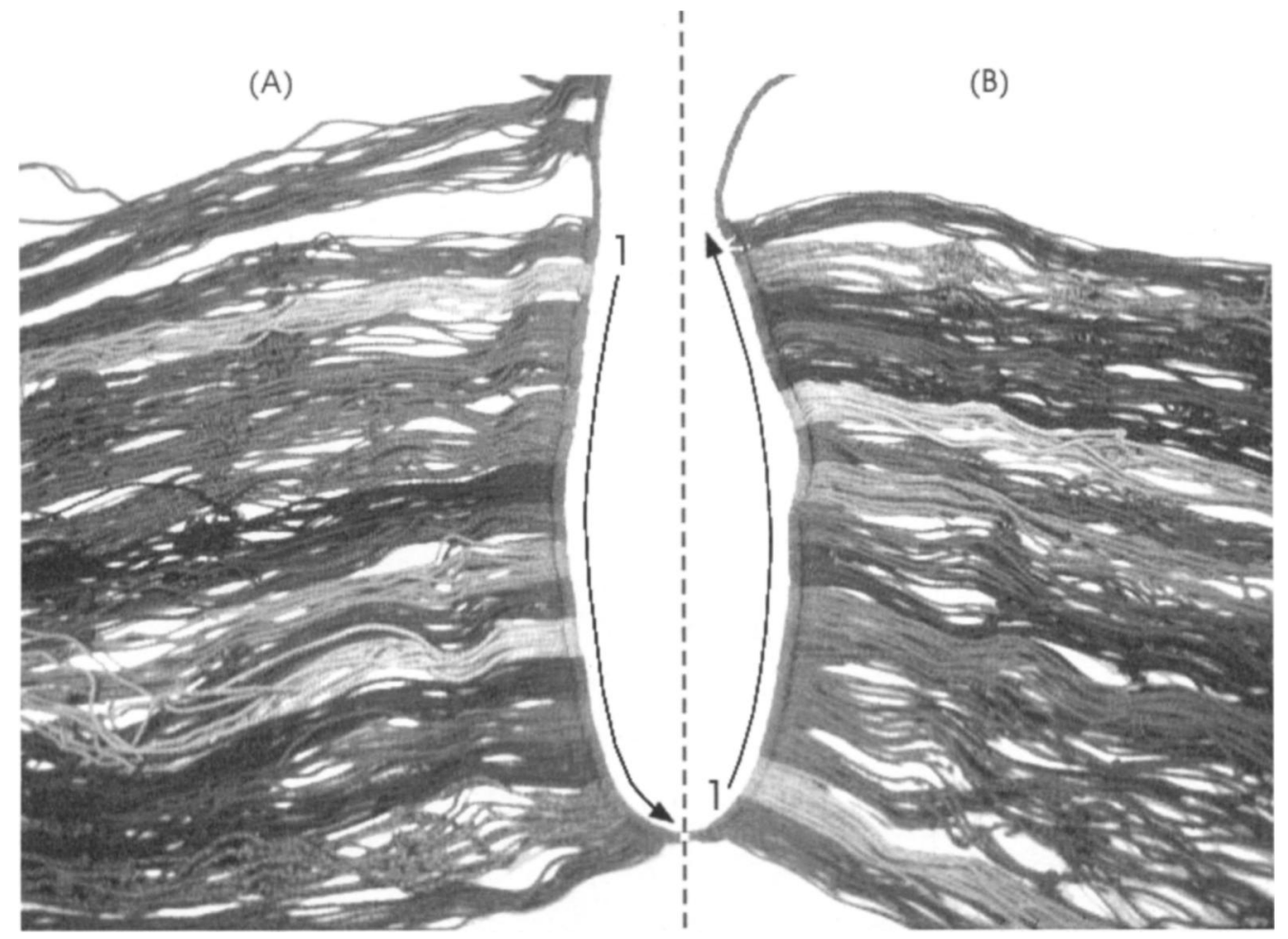

Figure 4. The two-part organization of Khipu AS114.

above calls to mind the observations on tribute accounting readjustments made by Catherine Julien (1988) in her seminal study, "How Inca Decimal Administration Worked." Such counts and recounts of populations were also common practices in the colonial census procedures (for which records were kept both in written documents and in khipu) known as visitas and revisitas (see Guevara-Gil and Salomon 1994). It is also instructive to note that, in the early cuneiform tablets from Mesopotamia, similar "close matches" occur in certain accounting circumstances, for instance, in the debit and credit versions of tablets pertaining to the same transaction, as well as in successive yearly accounts of such things as census or tribute records (see Nissen et al. 1993:43). ${ }^{9}$ In sum, I suggest that the differences in numerical values in Parts $A$ and B in Figure 5 may have been the result of the khipu keeper having recorded different numbers of people (or some other variable resource) within a certain community or region in or around Ica at two different times. The colors of strings in the various sections of the two parts of this sample might have fulfilled identity-labeling functions; that is, although the numbers of people in the different groups changed in the two different accounting periods, their identities as groups or classes of people remained the same. We will return later to the question of identity labels in another set of matching khipu.

After this expanded analysis of AS114, we return to the earlier discussion of the pair of matching khipu in Figure 3. We saw in that pair of samples that 10-string segments on AS114 and AS123 contained matching data. Having now examined the overall bilateral organization and recording of numerical information in AS114, we can focus on the segment of Figure 5 in the far left-hand column labeled Section 2. We now see that Section 2 in Part A of AS114 (Figure 5) is the same segment of strings that was earlier compared with Khipu AS123, in Figure 3. I suggest that what we may be viewing in these two figures is an example of a "source khipu" for a segment of a larger, summarytype khipu. The 10-string segment from Khipu AS123 shown in Figure 3 might represent the source of the information recorded in Section 2, Part A of Khipu AS114, in Figure 5. Thus, we might 
A

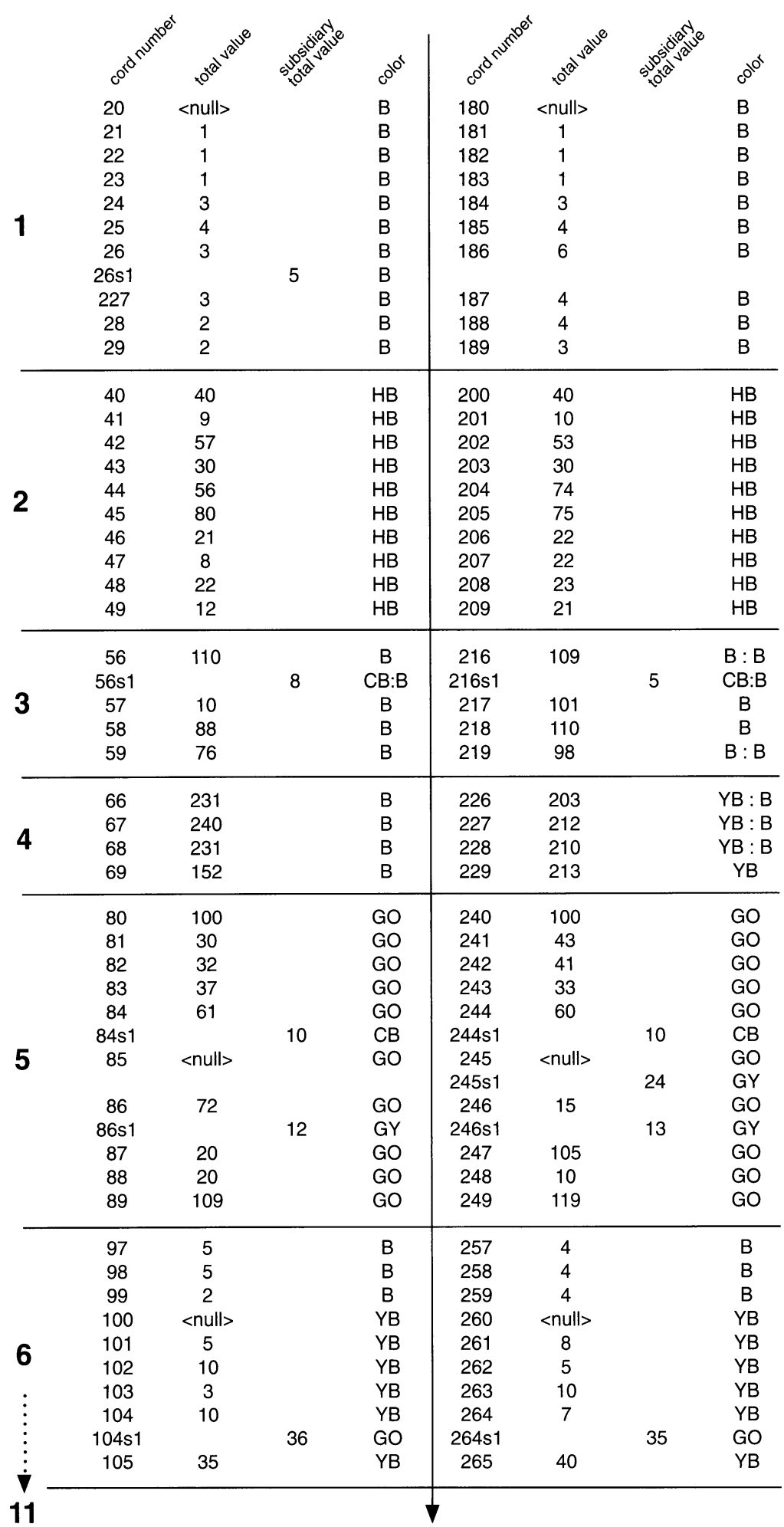

Figure 5. Knot values and colors in the first six paired sections of AS114. ${ }^{7}$ 
say that Khipu AS123 could have been the account of an ayllu-level record keeper, part of whose information was incorporated in Section 2 of AS114, Part A. This would suggest that AS114 could have been composed from 11 different (ayllu-based?) khipu keepers' accounts, one for each section shown in Figure 5.

With the aid of the khipu database under development at Harvard University, we have been able to identify several other examples of reassessment, or readjustment, khipu accounts similar to that seen in AS114. Another such example is shown in Figure $6 \mathrm{a}$ and $\mathrm{b}$. Figure $6 \mathrm{a}$ shows the numerical values and colors of the 13 strings composing khipu sample AS116, with Ica provenance, in the Museum für Völkerkunde in Berlin (VA 47125). Figure $6 \mathrm{~b}$ shows the numbers and colors of strings on AS150, a sample also from Ica in the Berlin collection (VA 47109). It contains a total of 27 pendant strings.

In Figure 6, we see that the numerical values on the matching segments of these two khipu are identical or very close. However, the differences are regular in the sense that, when the paired values differ, the value on AS116 is always less than its mate in AS150. Thus, like the two half-khipu accounts in AS114, the two samples in Figure 6 may count the same items at two different times; in this case, however, the numbers of items counted will, in all cases, have increased over the time period concerned (if Khipu AS116 preceded AS150), or they will have decreased (if AS150 preceded AS116). The colors of the strings in this pair are also quite similar and contain the same general patterning of the alternation of a white $(\mathrm{W})$ string and a string colored either moderate reddish brown (RB), in AS1 16, or brownish orange (SB), in AS150. Such consistency in color patterning may indicate that the two khipu recorded the same identities, or classes of objects.

\section{Three-Way Khipu Matches}

We have looked at matches in either two khipu or the two halves of a single sample. In this section, we will look at two significantly more complex examples of matches, each involving three khipu. The first is drawn initially from material presented by Carol Mackey's (1970) Knot Records in Ancient and Modern Peru. The samples were included in an archive composed of 21 khipu discovered at the site of Puruchuco, located in the Rimac Valley, about $11.5 \mathrm{~km}$ northeast of Lima. This cache was inside an unslipped olla under the floor of a small house built against the wall of a large "villa" at Puruchuco (Mackey 1970:65-66). The three cotton khipu are labeled No. 2, No. 3, and No. 9 in Mackey's numbering scheme and are composed (respectively) of 74, 71 and 62 pendant strings.

Given the size and complexity of the three Puruchuco khipu, it is possible only to illustrate summary information recorded on them (see Figure 7a-c). In Figure 7, we see the number values and color designations ${ }^{10}$ for pendant strings on samples No. 2 (Figure 7a), No. 9 (Figure 7b), and No. 3 (Figure 7c). This information was initially taken from Carol Mackey's (1970) study. However, Carrie Brezine and I recently undertook a complete restudy of these three (and all other available) khipu in the Puruchuco archive (Urton and Brezine 2005; see the data tables of the Puruchuco archive at: http://khipukamayuq.fas.harvard.edu/). The khipu labeled No. 9 by Mackey (Figure 7b) was not in the Puruchuco Museum at the time of our study (I am unsure of the whereabouts of this sample). Each set of columns in Figure 7 represents the rendering (respectively) of: the color designation notations used by Mackey (e.g., Figure 7a = CGBC2BC...), and the numerical values of knots tied onto pendant strings (e.g., Figure $7 \mathrm{a}=$ $1113821 \ldots)$ as read either by Mackey or by Urton and Brezine. A few of my own readings of numerical values of knots on Khipu No. 2 and No. 3 (Fig. $7 \mathrm{a}$ and c) differed from those recorded by Mackey (1970). ${ }^{11}$ Therefore, some of the values in Figure 7 have been changed from the values reported by Mackey.

What is immediately of interest is the striking similarity in numerical values registered on the three khipu in Figure 7. As for the nonmatching numerical values on these three khipu, these are keyed to the particular relationships that obtain between Figure $7 \mathrm{a}$ and $7 \mathrm{c}$ and the central khipu, $7 b$. Specifically, if a number value does not match across all three samples, one or the other of two circumstances is indicated in Figure 7. In those cases in which Khipu No. 9 (Figure 7b) shares a particular numerical value with Khipu No. 2 (Figure 7a), but where this value does not appear on Khipu No. 3 (Figure 7c), an arrow points from that number in Figure 7a to the corresponding number 
Ica AS116

Ica AS150

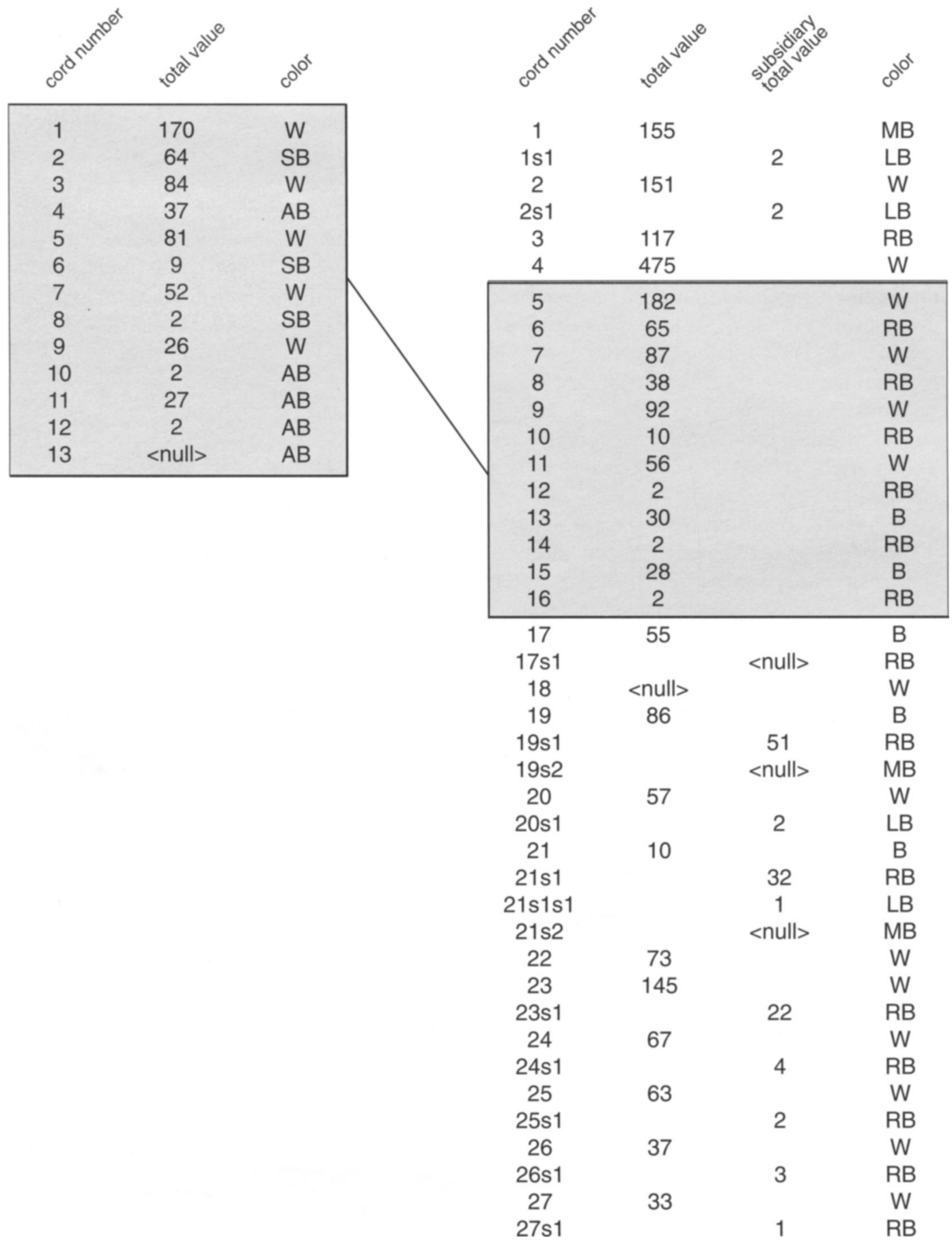

Figure 6. Khipu matching pair: a. AS116 and b. AS150. ${ }^{7}$ 
(a) - \#2

COLOR VALUE

C 1

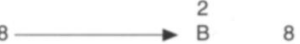

2

1
3
1

56

5

1213

64

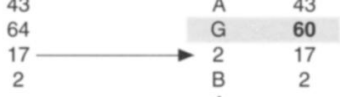

(b) - \#9

COLOR VALUE

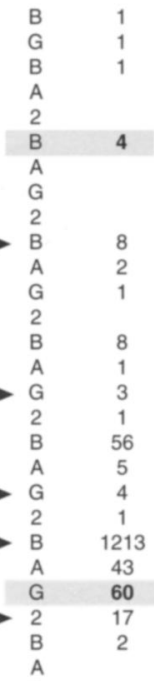

(1)

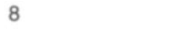

8

1
57

5
2

1236

46
59
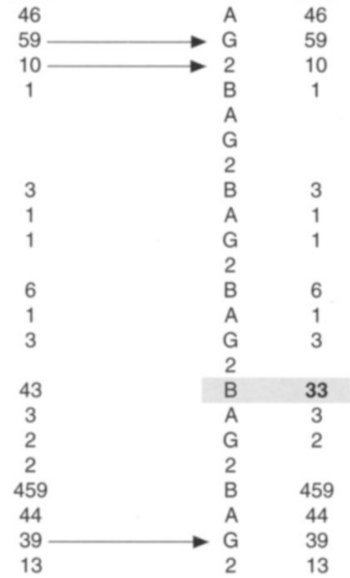

(c) $-\# 3$

color VAluE

\begin{tabular}{|c|c|}
\hline C & 1 \\
\hline B & \\
\hline C & \\
\hline G & \\
\hline 2 & \\
\hline B & \\
\hline C & \\
\hline G & 1 \\
\hline 2 & \\
\hline B & 1 \\
\hline C & \\
\hline G & \\
\hline 2 & \\
\hline B & 3 \\
\hline C & \\
\hline G & \\
\hline 2 & \\
\hline B & 7 \\
\hline C & 2 \\
\hline G & 1 \\
\hline 2 & \\
\hline B & 8 \\
\hline C & 1 \\
\hline G & \\
\hline 2 & 1 \\
\hline B & 56 \\
\hline C & 5 \\
\hline G & \\
\hline 2 & 1 \\
\hline B & 1212 \\
\hline C & 43 \\
\hline G & 64 \\
\hline 2 & 16 \\
\hline B & 2 \\
\hline $\mathrm{C}$ & \\
\hline G & 1 \\
\hline B & 8 \\
\hline C & 1 \\
\hline G & 1 \\
\hline 2 & \\
\hline B & 8 \\
\hline C & 1 \\
\hline G & 3 \\
\hline 2 & 1 \\
\hline B & 57 \\
\hline C & 5 \\
\hline G & 6 \\
\hline 2 & 2 \\
\hline B & 1236 \\
\hline $\mathrm{C}$ & 46 \\
\hline G & 57 \\
\hline 2 & 12 \\
\hline B & 1 \\
\hline C & \\
\hline G & \\
\hline 2 & \\
\hline B & 3 \\
\hline C & 1 \\
\hline G & 1 \\
\hline 2 & \\
\hline B & 6 \\
\hline C & 1 \\
\hline $\mathrm{G}$ & 3 \\
\hline 2 & \\
\hline B & 43 \\
\hline C & 3 \\
\hline G & 2 \\
\hline 2 & 2 \\
\hline B & 459 \\
\hline $\mathrm{C}$ & 44 \\
\hline G & 38 \\
\hline 2 & \\
\hline
\end{tabular}

Figure 7. Three matching khipu from Puruchuco. ${ }^{7}$ 
in Figure $7 \mathrm{~b}$. This is intended to suggest that Figure 7a may have been the source for that particular numerical value in the Figure $7 \mathrm{~b}$ sample. And second, in a few cases, the khipu in Figure $7 b$ (Khipu No.9) contains numbers that are not found in either Khipu No. 2 or No. 3; in such instances, these numbers in Figure $7 \mathrm{~b}$ are shaded. This latter notation is meant to indicate that this value is unique to khipu No. 9 (and perhaps was obtained from some other source). It should also be stated that no values are shared only between Khipu No. 3 (Figure 7c) and Khipu No. 9 (Figure 7b), and no values exist both in Figure $7 \mathrm{a}$ and Figure $7 \mathrm{c}$ that are not also found in Figure $7 \mathrm{~b}$. As a result of these observations, we can conclude that the khipu in Figures $7 \mathrm{a}$ and $7 \mathrm{~b}$ are most alike and that those in Figures $7 \mathrm{a}$ and $7 \mathrm{c}$ are least alike.

What do the above observations suggest about the relationships among these three khipu from Puruchuco? I contend, first, that the three khipu depicted schematically in Figures $7 \mathrm{a}-\mathrm{c}$ represent different versions of the same accounting circumstance. For example, these may be the khipu of three different khipu keepers charged with keeping the same account, as Garcilaso's statement at the beginning of this article suggests occurred quite commonly in Inka record keeping.

It is important to state that the numerical values on the three khipu in Figure 7 are, on the whole, close enough to each other that I do not think we are confronted here with a more complex, threekhipu version of the kind of paired accounts discussed in the preceding section. It was argued there that the differences in those particular paired khipu (see especially Figures 5 and 6) resulted from different records produced in successive accountings. In the case of the three khipu shown in Figure 7, I think that the values recorded are close enough among themselves to support the suggestion that these are three different versions drawn from the same accounting episode, or circumstance.

Second, I suggest that the accounts in Figures $7 \mathrm{a}$ and $7 \mathrm{~b}$ were more similar to each other than those between either $7 \mathrm{a}$ and $\mathrm{c}$ or $7 \mathrm{~b}$ and $\mathrm{c}$ either because the khipu keepers who constructed the khipu in $7 \mathrm{a}$ and $7 \mathrm{~b}$ saw things more nearly alike (and differently from the khipu keeper who constructed the khipu in 7c) or because the khipu in $7 \mathrm{~b}$ was the "adjusted," or "standardized," account. The latter suggestion would imply that the khipu keeper who retained the khipu in Figure $7 \mathrm{~b}$ was charged with resolving differences between the khipu keepers who constructed the accounts recorded in the samples in Figures $7 \mathrm{a}$ and $7 \mathrm{c}$ and that he/she more commonly agreed with or accepted the data provided by $7 \mathrm{a}$ than those provided by $7 \mathrm{c}$.

A third observation that would seem to support the interpretation given above is that the color coding used by the Figure $7 \mathrm{~b}$ khipu keeper was more similar to that used by the maker of the khipu in $7 \mathrm{a}$ than it was to that used by the maker of the khipu in 7c. Specifically, the khipu in Figure $7 \mathrm{~b}$ most commonly resorts to the color sequence: BAG2 (see Note 10 for translation of Mackey color notations); the Figure 7a khipu also commonly uses BAG2, but with an occasional addition (at the top of the column) of BCG2 (see Note 10); the khipu in Figure $7 \mathrm{c}$, on the other hand, primarily displays the color patterning labeled BCG2 and contains no instance of the color sequence BAG2. Thus, the Figure $7 \mathrm{~b}$ khipu most commonly shares both its numerical values and its color designations with the khipu in $7 \mathrm{a}$, while also sharing much of its numerical (though not its color) information with that in $7 \mathrm{c}$. In summary, I argue that Figures $7 \mathrm{a}-\mathrm{c}$ represent a set of khipu that were the products of data collection and accounting adjustments that went on among either two or three khipu keepers who were charged, as Garcilaso suggests they always were, with "keeping the same account."

Our second example of a three-way group of matching khipu comes from the northern Peruvian (Chachapoyas) site of Lake of the Condors (Lerche 1999; von Hagen 2000; von Hagen and Guillén 1998). An archive of 32 khipu was included with the 220 mummy bundles and associated burial goods found in two rock overhang sites around the lake. Ten were too fragile and fragmentary to allow for examination. Thus, $22 \mathrm{khipu}$ from this site are available for study (see descriptions at http:// khipukamayuq.fas.harvard.edu/).

Because they were found with relatively good archaeological context, the Lake of the Condors khipu seemed to offer great promise in allowing us to identify matches of numerical and other types of information among samples. During the first week after we had begun querying the data from the Chachapoya archive in our database, we encountered a quite remarkable set of matches 
among three of the samples: UR6, 9, and 21. ${ }^{12}$ Now, I have previously published an extensive analysis of one of these khipu-UR6 (Urton 2001). In that study, I argued that this large and elaborate khipu represented a two-year calendar that was used in the organization and accounting of tribute labor in central Chachapoyas in late prehispanic and possibly early colonial times. I will begin by briefly reviewing the features of this sample that led me to the calendrical hypothesis, as this will set the stage for the analysis of the matches recently discovered between Khipu UR6 and two other samples.

Khipu UR6 is composed of a total of 762 pendant cords; 730 of these cords are organized into 24 sets of strings, each set of which is made up of 29 to 31 pendant cords. The magnitude and range of the numbers of cords suggested to me that they might represent a framework of 24 month-like units. The 24 sets of cords are composed of paired groups of: (a) 20,21, or 22 pendant cords that are attached directly to the primary cord; and (b) 8, 9, or 10 pendant cords attached to the main cord indirectly, by means of what I refer to as "loop pendants." Loop pendants are composed of pendant cords attached to a string whose two ends are attached to the primary cord; thus, the string, with its attached pendant cords, hangs down (in a "loop") from the primary cord (see Urton 2001:136-138, Figures 5 and 7). I argued that the 730 pendant strings organized into 24 month-like sets, each composed of 29-31 pendant cords, provided a calendrical framework for accounting for tribute labor over a period of two twelve-month solar years (i.e., $2 \times 365=730$ ). The calendrical structure of Khipu UR6 is shown in schematic form in Figure 8. Groups of pendant strings that do not conform to the month-like organization of pendant strings in Khipu UR6 are circled.

I also documented in my earlier study that the numerical values of knots tied into the 730 pendant strings that compose the two-year calendar contain a total count of 2,962. ${ }^{13}$ I suggested that this knot count total represented an actual accounting of the ideal organization of tres guarangas (3,000 tribute payers) that were said, in Spanish documents produced in this region during the 1540 s- 70 s, to have been enumerated on a khipu that was at that time in the possession of a native Chachapoya khipu keeper in the area named Guaman (Schjellerup
1997; Espinoza S. 1967; Urton 2001). I would note that the population that lived in the immediate area of Lake of the Condors at the time of the conquest was composed of people belonging to the Chilchos ethnic group and that the Chilchos were organized into nine ayllu (Lerche 1995). Thus, Khipu UR6 may represent an account of the labor service performed by the Chilcho mit'ayuq (state service workers) either over two different years, or in two different accounting groups (one of approximately 1,000 and another of approximately 2,000 workers) in a single year, during late prehispanic times.

With this background, we turn to the matches that were recently identified between Khipu UR6 and two others from the archive at Lake of the Condors. Table 1 presents the author's record of numerical values registered in the knots tied into all the pendant cords of UR6. (Note: Pendant strings with null value are eliminated from the accounting in Table 1.) Table 1 is divided into four half-year segments, labeled (a)-(d). The groups of numbers below the dotted line in Table 1 represent the knot values on pendants cords in this section of the khipu that do not conform to the calendrical structure of UR6.

The segment of the calendar that we will be most directly concerned with here, as it contains the information matching two other khipu, is an approximately four-month period that extends from near the beginning of the thirteenth through the end of the sixteenth months. This is the portion of Section (c) - the third six-month period of the two-year calendar - that appears in bold italics in Table 1. (I will explain below why several additional sets of numbers inside and outside the italicized section in Table 1 are underlined.)

The two khipu that match the four-month section of data in bold italics in Table 2 are UR9 and UR21. These three samples are brought together in the three groups of columns in Figure 9. Each set of columns in Figure 9 contains the cord numbers and their respective numerical values and color(s). In Figure 9, the left-hand set of columns pertains to Khipu UR9, the central set of columns is taken from the four-month segment of UR6 defined above, and the right-hand set of columns pertains to UR21. The designation "LP_," which appears in the left hand column in the central set of columns (i.e., UR6), refers to "Loop Pendants" (see above).

The similarities between the numerical values 
Pendant/Loop Pendant Pairs

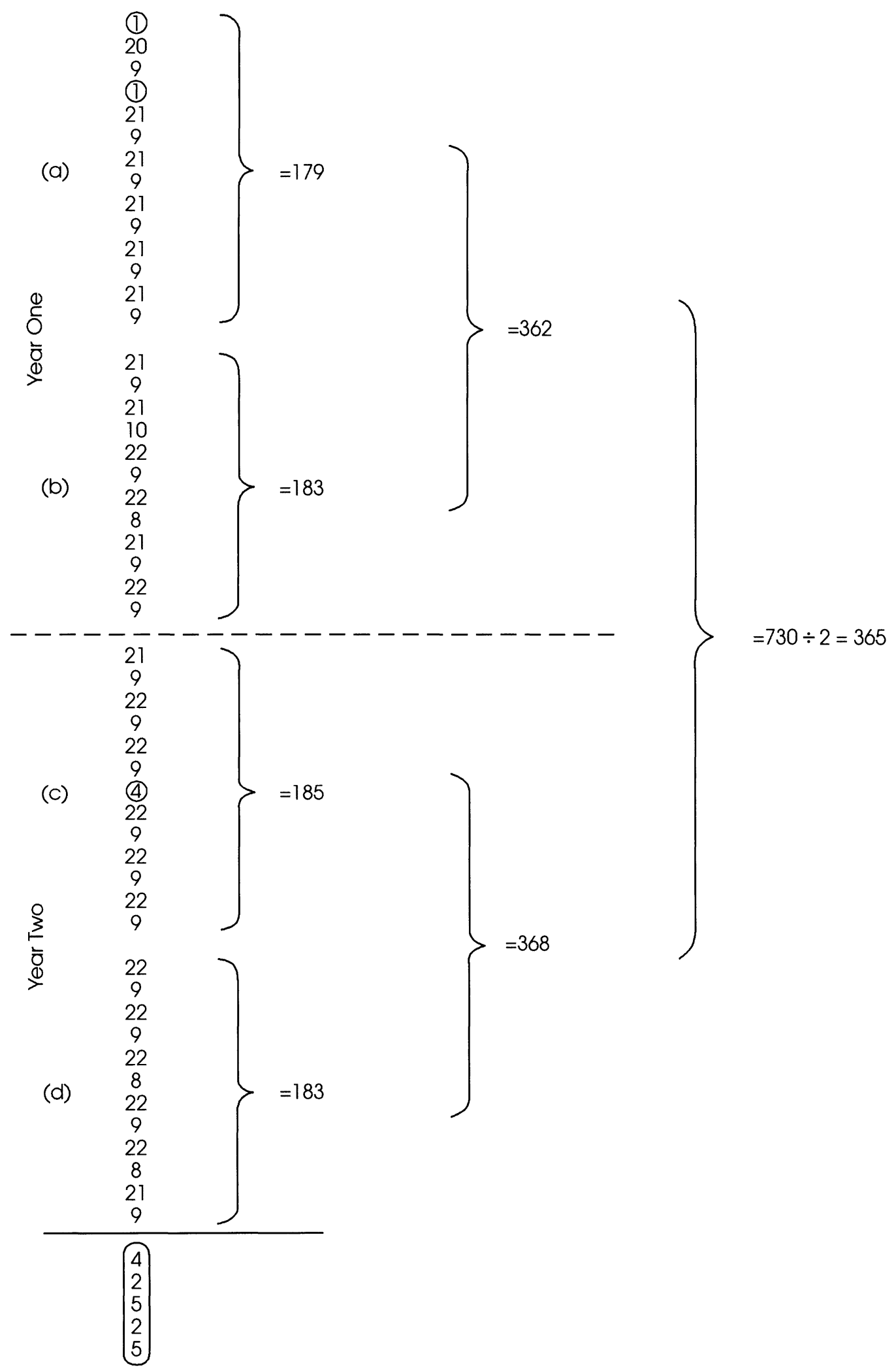

Figure 8. The calendrical organization of pendant strings on Khipu UR6. 
Table 1. Numerical Values on Khipu UR6.

\section{UR 6}

(a)

2, 1, 1, 1, 1, 13, 1, 1, 1, 1, 1, 9, 2, 1, 2, 2, 4, 1, 2, 5,

$1,4,1,15,2$,

$1,1,7,1,7,12, \underline{30,65,20}$,

$1,1,2,1,1,15,10$,

$1,3,1,1,4,2,1,1,2,1,12,2,15,3,3,2,4,1$,

$1,1,4+3,1,1,1+1,3+3$,

$1,1,1,1,10,2,1,11,2,7,2,7,2,8,2,1+1$,

$2,1,1+1,3+2,1,1$,

$1,1,1,6,1,2,1,1,2+1,4,9,2,5,2,9,2,2$,

$18+2,2,4+2,2,16+4,1,10+3+6,521,10+8+6$,

$1,1,2,2,2,7,1,1,10,3,7,3,2,2$,

$14,2,1,7,2,1,6,1, \underline{30,80,20}$,

$1,3,2,1,3,1,1,1,10,18,2,1$,

$1,1,1,1,6$,

(b)

$1,1,3,1,3,1,8,6,9,8,3,1$,

$2,1,2,4,1,1$,

$1,2,6,1,1,1,13,9,7,6,2$,

$8,2,5,1,9,1,15,40,22$,

$2,2,2,2,3,3,9,3,2,1,12,1,6,1,6,9,19$,

$2,1,9,4,4,1,1, \underline{20,71,35}$,

$2,2,2,3,1,1,4,1,2,1,3,1,15,21,2,5,1$,

$1,1,5,1,5$,

$2,2,1,1,3,3,1,13,1,3,4,3,10,9,10,5$,

$2,3,5,1,1$,

$2,1,2,2,1,2,10,1,7,1,1,6,10,5,15,5$,

$7,1,5,1,5,1,12,35,20$,

(c)

2, 1, 1, 2, 2, 8, 1, 2, 9, 2, 5, 1, 2, 7, 14,

$2,1,8,4,3,1,1,20,61,20$,

$2,1,3,2,3,1,2,1,14,16,4,2,1$,

$1,4,1,1,5$,

$1,1,2,1,1,4,7,1,2,1,1,3,3,11,10,3,3$,

$2,1,3,1,5,1$,

$1,1,1,1,10,9$,

$2,2,3,2,7,1,3,1,1,1,6,11,5,7,5$,

$6,1,5,1,5,1,1,11,35,20$,

$1,1,1,1,2,2,3,2,2,2,5,4,4$,

$1,4,1,1,2,1,10,40,16$,

$1,1,1,1,2,1,2,1,2,2,5,2,5$,

$1,1,1,5$,

\section{(d)}

1, 1, 1, 3, 1, 1, 2, 3, 4, 4, 5, 2,

$1,1,1,3,1$,

$1,1,1,2,2,1,3,1,4,8,3,3,3$,

$5,1,3,1,3,1,10,30,10$,

$1,2,1,1,1,1,1,1,3,5,1,1$,

$1,2,1,3$,

$1,1,2,1,3,2,4,4,1,3$,

$1,3,1$,

$1,1,1,2,3,1,1,2,1,1,1,2,6,4,7,5$,

$4,1,3+1,1,2, \underline{10}, 1, \underline{30}, 2, \underline{10}, 1$,

$1,1,1,1,2,3,3$,

$1,3,1,2,3,20,7$,

$1,1,1$,

4,4 ,

$2,2,2,1,1$,

1,1 ,

$1,1,2+1$
Table 2. Identity Labels in Khipu UR6.

(a)

30-65-20

$30-80-20$

(b)

15-40-22

20-71-35

12-35-20

(c)

20-61-20

11-35-20

10-40-16

(d)

10-30-10

10-30-10 
registered in the three khipu shown in Figure 9 are striking. On the basis of these similarities, I argue that UR9 and UR21 may represent different versions, drafts, or cross-references (in the Garcilascan sense) of the information contained in the four-month segment of UR6. How might this complex set of matching numerical values on three different khipu from the archive at Lake of the Condors have come about? Phrased another way, what can this example of matching khipu accounts teach us about Inka record-keeping practices, at least in this far northern region of the empire? I believe there are two features of this set of matching khipu that we should focus on in order to arrive at an interpretation of the types of information recorded on these three samples and the way the information registered on them may have been compiled, compared, and synthesized.

The first feature I stress is that the match between samples UR9 and UR21 with UR6 involves about a sixth of the data (i.e., four out of 24 months) recorded on what I hypothesized earlier was a tributary calendar-UR6. Building on this earlier hypothesis, I now suggest that UR9 and UR21 represent accounts of ayllu laborers that were retained by two khipu keepers who were responsible for recording information pertaining to one or more ayllus whose service duty (or duties) fell during the four-month period in question. The two ayllu-level khipu keepers who retained samples UR9 and UR21 would have reported the contents of their respective khipu to a third, probably higher level, khipu keeper. The latter official-i.e., the khipukamayuq who retained UR6-would have had the responsibility for coordinating the accounts that came in to him from the khipu-keepers of numerous, different ayllus. All of this information was then synthesized into the single summary accounting knotted into khipu UR6.

This general interpretation of correspondences among the three Chachapoya khipu implies that additional ayllu-based khipu accounts may have existed from which the groups of workers assigned to the other 20 months recorded in UR6 were drawn up. We have studied closely the other khipu found at Lake of the Condors, but have not to date identified potential "source khipu" for other segments of UR6. This may imply that these ayllu-level khipu records were perhaps stored with the ancestral mummies of the other ayllus from the region and that these ancestral mummies, along with their khipu, may have been located elsewhere in the central Chachapoyas region.

It is relevant to note that accounting in fourmonth periods, as in khipu samples UR9, UR21, and a segment of UR6, was apparently a standard feature of Inka record-keeping practices. Such an accounting periodicity is suggested, for instance, in the testimony of Polo de Ondegardo (1916:146-147), who says that in Inka times, people delivered their tribute to Cusco on three occasions throughout the year; this suggests a $3 \mathrm{x}$ 4-month accounting periodicity (= 12 months). Juan de Matienzo notes a similar accounting periodicity in early colonial times as follows:

if any Indian requests something or accuses a principal of something, he cannot do so before the 'alcaldes' (mayors), but [he must do it] before the Spanish 'Corregidor,' and, if he [the Corregidor] is not available, before the Tucuirico, so that he [the Tucuirico] puts it in his quipo for the record, and every four months he goes with the quipo to the Corregidor in the city, so that he [the latter] expediently does justice about the complaints that he [the Tucuirico] brings by the quipo, without having to receive those who made the complaints when these are small things [Matienzo 1967:55; translated by R. T. Zuidema; my emphasis].

Thus, the fact that UR9 and UR21 contain some manner of accounting during what appears to be a four-month segment of UR6 accords well with what we learn from the chroniclers about Inkaic and early colonial accounting periodicities and practices. ${ }^{14}$

The second point that I want to focus on concerns a particular group-what I would term a class-of numbers contained in these three accounts. The two such three-term sets that are located within the matching khipu we have been examining (Figure 9) are: 20-61-20 and 11-35-20. The first of these three-term number sets is found in Table 1, Section c, at the end of line two; the second set is at the end of the highlighted sequence of numbers in Table 1 (i.e., Section c, line 9). As the numerical values in the highlighted section of Table 1 reveal, these two three-term number sets contain values that, while not large by an absolute standard, 


\section{I}
罗
$\stackrel{m}{4}$
$\begin{array}{lll}0 & 0 \\ 1 & 0\end{array}$
$\stackrel{m}{\Sigma} \frac{m}{4}$

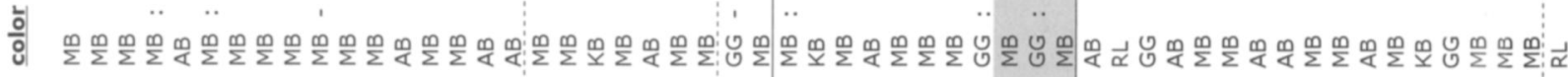

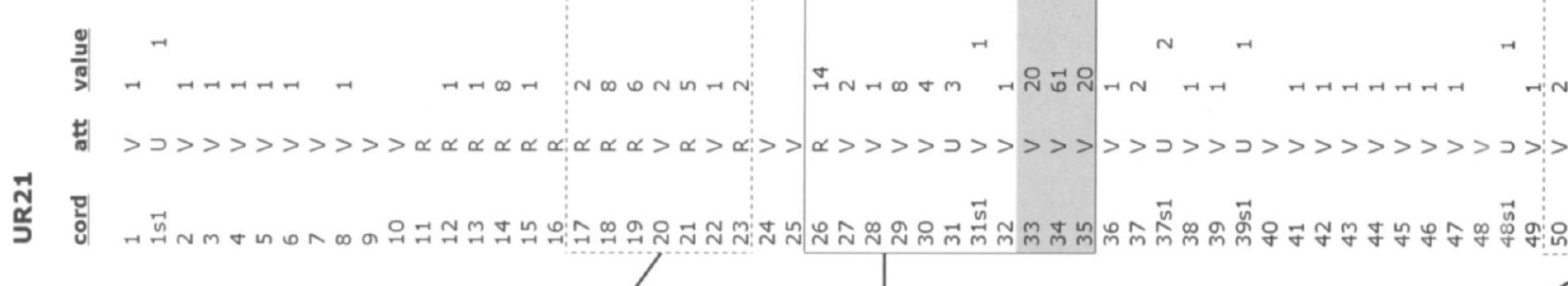

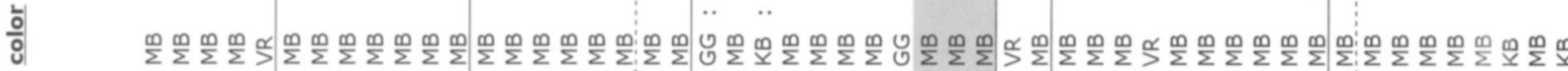
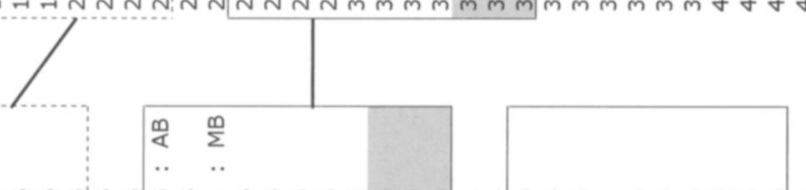

$\frac{0}{2}$

洁

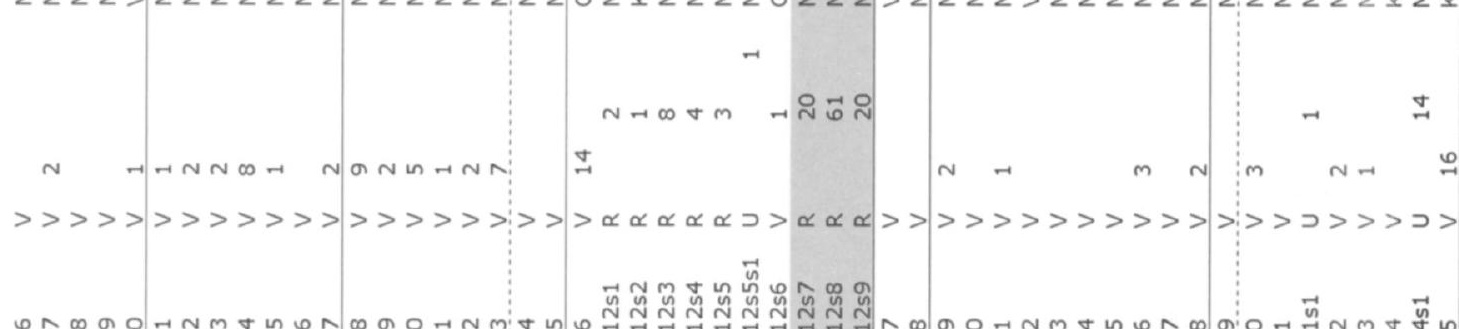

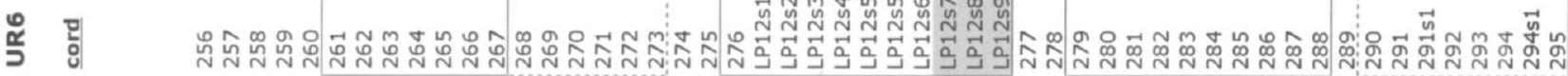

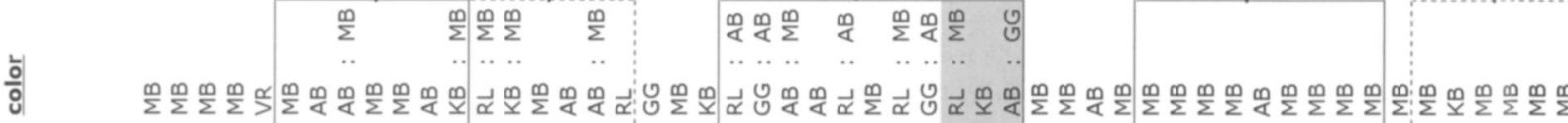

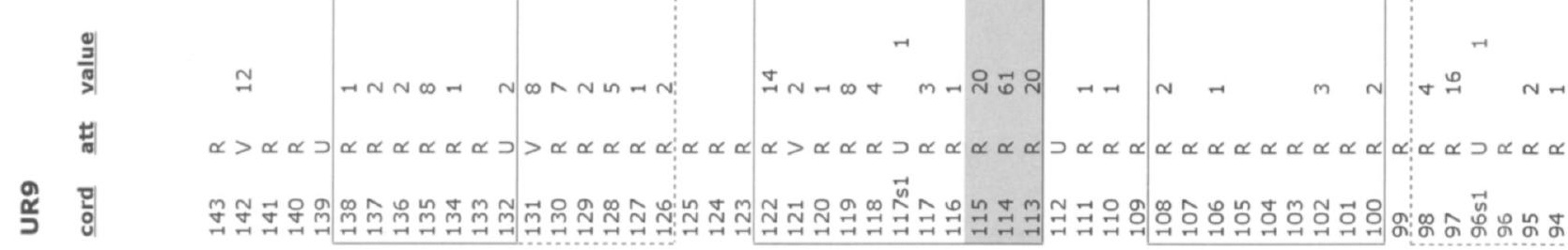


are nonetheless notably larger than the values recorded elsewhere in Section c (i.e., in the area that contains the matches between UR6 and Khipu UR9 and UR21). To be clear, the three-term values I am discussing are numerical values knotted into groups of three adjacent cords.

As seen in Figure 9, the first of the three-term sets mentioned above (20-61-20) is also found in UR9 and UR21; they are the sets of values on three strings indicated by shading in the upper section of numerical values recorded from each khipu. As for the second of the three-term number sets (11-3520), versions of this appear at the ends (bottoms) of the columns for UR6 and UR21 in Figure 9. Khipu UR9 does not terminate in a comparable three-term number series. However, the three final strings of this khipu are crinkled and twisted in a manner suggesting that each of the strings was previously knotted. Therefore, I think that UR9 may also at one time have ended in the three-term numerical set 11-35-20.

What can have been the significance, or the meaning, of the three-term number sets identified above? In order to address this question, we should look again at all of the numerical data encoded in Khipu UR6, as these are displayed in Table 1. By looking at the underlined values, we see that there are, in fact, 10 three-term number sets spread across this khipu. (The bottom-most of these number sets appears to be composed of five numbers [10-1-302-10]; however, the second and fourth numbers in this series [i.e., 1 and 2] are tied onto subsidiary strings, which means that if we just read the values on the three adjacent pendant cords, they contain the three-term number set: 10-30-10.) Five of these number sets in Table 1 are located within each half of the two-year calendar of UR6. Table 2 presents the three-term number sets in their locations within the overall structure of UR6.

I advance the hypothesis that these 10, threeterm number sets represent labels, or emblems, relating to the information recorded on Khipu UR6. ${ }^{15}$ In this regard, I note that all 10 of these sets occur on the final three strings of loop pendants. Thus, loop pendants appear to have been the carriers of identity labels, whatever the latter may have signified. Furthermore, several of the three-term number sets appear to represent paired sets; for example, in Section a, we find the possible paired set $(30,65,20) /(30,80,20)$; in Sections b and c we find the set $(12,35,20) /(11,35,20)$; and in Section $d$ there is the set $(10,30,10) /(10,30,10)$.

What could have been the meaning and significance in the Lake of the Condors khipu archive of the 10 three-term number sets and their "pairing," as suggested above? In the first place, if the threeterm number sets are, indeed, identity labels, then we must remove these as values in any tribute accounting, or assessment in Khipu UR6. This would clearly call into question my interpretation that the total knot count, including knot values on the "identity labels," on this khipu, pertained to an accounting of ca. 3,000 mit'ayoc in the Lake of the Condors region. That is, removing the identity labels as mit'ayoc counts produces annual (i.e., two-year) counts of 1,513 (= Year 1) and $601(=$ Year 2), for a two-year total of 2,114. This revised total is well beyond two of the standard waranqa $(1,000)$ accounting units and is not (to my knowledge) close to a tributary count recorded in colonial documents from this region. Given the present uncertainty in our knowledge of the referents of the accounts composing the Chachapoya (or any other!) khipu archive, we must be content to allow both interpretations-i.e., that UR6 represents an accounting of ca. 3,000 mit'ayuq, or that it is an accounting of 2,114 of something with 10 identity labels - to stand as equal possibilities.

If we do, however, pursue the implications of the three-term number sets as labels, or names, I ask: could these perhaps have represented labels that identified the social groups-e.g., ayllus - that occupied this area in late prehispanic to early colonial times? (The Chilchos ethnic group was divided into some nine ayllus [Espinoza Soriano 1967; Lerche 1995].) Perhaps the labels in UR6 identified a collection of local ayllus. In this regard, Lerche (1995:58-61) has argued that a moiety organization was common among various ethnic groups in the Chachapoyas region. Thus, I would ask if the pairing of three-term number sets suggested above could indicate the existence in this account of ayllu organized into upper (hanan) and lower (hurin) moieties (see Fossa 2000 on this point). Or perhaps the three-term number sets identified tasks that were to be performed during the calendrical period(s) in question, or the labels of temporal periods (e.g., seasons) themselves during the two-years recorded in Khipu UR6. Whatever their referents, these three-term number sets appear to represent 
the first identifiable examples of "names," or labels, recorded on khipu. ${ }^{16}$

\section{Conclusions}

Where have the data, observations, and interpretations presented in this study taken us in terms of our attempts to understand the procedures and practices of encoding and decoding information in archives of Inka khipu? I think there are several implications and conclusions we can draw that will help move us along toward our ultimate goal of decipherment—or at least of determining whether or not these perplexing knotted string records are, in fact, decipherable.

The first implication is that Garcilaso's observations with respect to the existence of multiple khipu that recorded similar-or, as he says, "the same"-information can now be confirmed, at least at a general level. One of the most intriguing reflections on the information presented herein is that these examples of duplicate and overlapping accounts are similar to bookkeeping procedures evidenced in the earliest known state-level system of accounting - that of the cuneiform tablets of ancient Mesopotamia (e.g., Steinkeller 2003:42). As Nissen et al. (1993:30) note in their study of early bookkeeping techniques in Mesopotamia, "[t]he tablets were seldom isolated information transmitters; rather, they almost without exception represent a part of running book-keeping procedures in which pieces of information from one tablet were transposed to another." Replacing "tablet" with "khipu" in this quotation gives an only slightly overstated characterization of the place of duplication in prehispanic Andean record keeping as it was characterized by Garcilaso. For example, this quote calls to mind the kind of matching accounts seen, for instance, in Figures 2, 3, and 9 in which information recorded in one or two khipu appears to be reproduced in another, usually larger one. These examples of matching and overlapping khipu make it imperative that we devote more effort than has been expended to date building up a corpus of matching khipu and thereby both expanding and deepening our understanding of what must have been a central feature of khipu record-keeping practices in the Inka empire. In short, we now have the prospect of, as well as the mandate for, beginning to identify and collate archives of interrelated, cross-referenced khipu from different regions around the empire.

The second observation and conclusion is that a few of the matching khipu examined herein suggest that we may be able to recognize khipu that are related to each other in relative chronological terms, as in the negotiation of accounts over time. This feature has been seen in those examples with close, though not exact, matches. I have suggested that a couple of these may represent successive accounts of the same accounting task performed at two different points in time, or as recorded by two different khipu keepers who saw or heard different accounts of a body of data for which they bore equal responsibility. The hope of being afforded a view into the negotiation of accounts over time promises to considerably deepen, and problematize, our view of khipu accounts and accounting practices.

In this regard, we can make another interesting comparison to bookkeeping procedures that appear in the early cuneiform tablets from Mesopotamia. Nissen et al. (1993) point out that there are several examples of tablets linked to each other in terms of the balancing of debits with credits and of the posting of accounts on some product or activity in consecutive years. In such examples, the amount of goods posted in a debit tablet (or in one year) only approximates the amount posted in a credit tablet (or in the next year; Nissen et al.1993:43). Such credit/debit (or successive annual) postings could account for the kinds of "close matches" between khipu that we have encountered in this study (e.g., see Figures 5 and 6).

The third observation involves a matter that has been the subject of considerable speculation and controversy in recent years. This is the question of the degree to which any two khipu keepers may have been able to interpret, or read, each other's khipu accounts. The issue here is raised by a midseventeenth-century chronicler of Inka history and culture, Bernabé Cobo. In characterizing khipu record-keeping principles and procedures, Cobo made the following quite novel (see Urton 2002:17) statement:

[N]ot all the Indians were capable of understanding the quipos; only those dedicated to this job could do it; and those who did not study quipos failed to understand them. Even 
among the quipo camayos themselves, one was unable to understand the registers and recording devices of others. Each one understood the quipos that he made and what the others told him [Cobo 1983 (1653):253-254].

According to Cobo's account, one might expect that any given khipu was readable only by the khipu keeper who made that particular one (see the discussion of this issue in Urton 2003:19-26). However, the examples of matching khipu presented in this paper render this view highly untenable. That is, is it reasonable to think that the makers of the three Puruchuco khipu discussed above (see Figure 7) were unable to read or interpret the information in each other's khipu? Or can we presume that the two Chachapoyas khipu keepers who retained UR 9 and 21 were unable to read and interpret the portion of UR6 that so closely matched the information in their own records (see Figure 9)? I believe the information presented herein renders Cobo's insistence on the absence of some level of conventionality in the khipu unsupportable.

The fourth implication concerns the three-term number units identified in the Chachapoya khipu, UR6, 9, and 21. What can these number series have meant? How might they have been interpreted in this particular accounting context? Can the threeterm number units have perhaps been logographlike sign units, which identified group (e.g., ayllu) identities? Might they have instead indicated tasks to be undertaken, or the times in which such tasks should be performed? Given the rudimentary state of our understanding of such terms and of their possible pairing within and across the two years accounted for in Khipu UR6, we cannot be too insistent on any one interpretation of the significance of these apparent emblems or labels. Whatever we finally determine with regard to the intended referent(s) of these three-term number sets, they appear to offer an intriguing set of characters for future study.

Finally, perhaps the most important implication of the material presented here and especially of the "archival" approach to khipu studies for which I have argued is the encouragement to record information on all extant khipu, no matter how incomplete they may be. In the past, there has been a decided tendency on the part of khipu researchers to study only those khipu that "add up." Such stud- ies focus on khipu that are complete (or relatively so) and for which one may make deductions regarding the arithmetic or mathematical operations that may have been employed in calculating the data recorded, or in searching for numerical patterns, rhythms, etc. Such studies have added immeasurably to our understanding of the khipu accounting system; however, this has come at the price of leaving aside or pushing into the background the analysis of samples that are not of immediate mathematical interest, or that are incomplete. The archival approach to khipu studies (which still allows for mathematical studies) is premised on the notion that all khipu, no matter how fragmentary or incomplete, should be studied and their data thoroughly recorded (see Radicati di Primeglio's [1964:9] encouragement on this point). A khipu fragment - even one bearing only a few cordsmay match another sample, and the two together may give us important, unique insights into the organization of Inka political economy and record keeping at local, regional, and state levels. Pursuing the strategy of recording all information on every extant khipu, no matter how incomplete or fragmentary, may allow us to re-assemble the long fragmented archives of this extraordinary ancient American accounting system.

Acknowledgments. Thanks to Carrie J. Brezine, Galen Brokaw, Frank Salomon (the latter two of whom were selfidentified reviewers for Latin American Antiquity) and R. T. Zuidema for reading, commenting on, and making invaluable suggestions for improvements on an earlier draft. I am responsible for all errors that remain. Thanks to my wife, Julia Meyerson, who prepared all but one of the illustrations (Figure 9 was prepared by Carrie Brezine). Thanks also to Luis Felipe Villacorta for his help, encouragement, and immense good will in support of my research in Lima, Peru. Thanks to the following individuals who helped make possible my research in various khipu collections: to Dr. Enrique Gonzales Carré and Ms. Rossana Mendoza Neyra for work at the site museum at Puruchuco, Lima, Peru; to Dr. Manuela Fischer and Dr. Marie Gaida for work at the Museum für Völkerkunde, in Berlin; to Dr. Craig Morris and Vuka Roussakis for work at the American Museum of Natural History, in New York; and to Dr. Sonia Guillen and Adriana von Hagen for work at the Centro Mallqui, Leymebamba, Chachapoyas, Peru. I acknowledge with deep gratitude the financial support provided by the following institutions or foundations: the National Science Foundation (grants: SBR9221737 and BCS-0228038), the Harvard University Faculty of Arts and Sciences, and the John D. and Catherine T. MacArthur Foundation. 


\section{References Cited}

Ascher, Marcia

2002 Reading Quipus: Labels, Structure, and Format. In Narrative Threads: Accounting and Recounting in Andean Khipu, edited by Jeffrey Quilter and Gary Urton, pp. 87-102. University of Texas Press, Austin.

Ascher, Marcia, and Robert Ascher

1975 The Quipu as a Visible Language. Visible Language 9:329-356.

1978 Code of the Quipu: Databook. University of Michigan Press, Ann Arbor (Available at: http://instruct 1.cit.cornell.edu/research/quipu-ascher/).

1988 Code of the Quipu: Databook II. Marcia and Robert Ascher, Ithaca, New York (Available at: http://instruct1.cit.cornell.edu/research/quipu-ascher/).

1997 Mathematics of the Incas: Code of the Quipu. Dover Publications, New York.

Cobo, Bernabé

1983 [1653] History of the Inca Empire. Translated and edited by Roland Hamilton. University of Texas Press, Austin.

Conklin, William J.

2002 A Khipu Information String Theory. In Narrative Threads: Accounting and Recounting in Andean Khipu, edited by Jeffrey Quilter and Gary Urton, pp. 53-86. University of Texas Press, Austin.

Espinoza Soriano, W.

1967 Los señorios étnicos de Chachapoyas y la alianza hispano-chacha. Revista Histórica 30:224-322.

Fossa, Lydia

2000 Two Khipu, One Narrative: Answering Urton's Questions. Ethnohistory 47:453-468.

Garcilaso de la Vega, El Inca

1966 [1609-1617] Royal Commentaries of the Incas. Translated and with an introduction by Harold V. Livermore. University of Texas Press, Austin.

Guevara-Gil, Armando, and Frank Salomon

1994 A 'Personal Visit': Colonial Political Ritual and the Making of Indians in the Andes. Colonial Latin American Review 3:3-36.

Guillen, Sonia E.

1999 Arqueología de emergencia: inventario, catalogación y conservación de los materiales arqueológicos de los mausoleos de la Laguna de los Cóndores. Final report submitted to the Instituto Nacional de Cultura, Lima.

Julien, Catherine J.

1988 How Inca Decimal Administration Worked. Ethnohistory 35:257-279.

Lerche, Peter

1995 Los Chachapoya y los símbolos de su Historia. César Gayoso, Lima, Peru.

1999 A Grave Case of Robbery. Geographical 71:18-23.

Locke, L. Leland

1923 The Ancient Quipu, or Peruvian Knot Record. American Museum of Natural History, New York.

Mackey, Carol

1970 Knot Records in Ancient and Modern Perú. Ph.D. dissertation, University of California, Berkeley. University Microfilms, Ann Arbor.

Matienzo, Juan de

1967 [1567] Gobierno del Perú, edited by Guillermo Lohman Villena, Travaux de l'Institut Français d'Études Andines, Vol. 11. Lima.

Nissen, Hans J., Peter Damerow, and Robert K. Englund

1993 Archaic Bookkeeping: Writing and Techniques of Eco- nomic Administration in the Ancient Near East. University of Chicago Press, Chicago and London.

Nordenskiöld, Erland

1925 The Secret of Peruvian Quipu. Comparative Ethnographical Studies. 6, Part 1. Goteborg.

Polo de Ondegardo, Juan

1916 [1571] Los errores y supersticiones de los indios sacados del tratado y averiguación que hizo el Licenciado Polo. Colección de Libros y Documentos Referentes a la Historia del Perú, Vol. 3. Imprenta y Librería San Martí, Lima.

Radicati di Primeglio, Carlos

1949-50 Introducción al estudio de los quipus. Documenta: Revista de la Sociedad Peruana de Historia 2 (1949-50):244-339.

1964 La "seriación" como posible clave para descifrar los quipus extranumerales. Biblioteca de la Sociedad Peruana de Historia. Monographs, No. 6. Universidad Nacional Mayor de San Marcos, Lima.

Salomon, Frank

2002 Patrimonial Khipu in a Modern Peruvian Village: An Introduction to the 'Quipocamayos' of Tupicocha, Huarochirí. In Narrative Threads: Accounting and Recounting in Andean Khipu, edited by Jeffrey Quilter and Gary Urton, pp. 293-319. University of Texas Press, Austin.

Schjellerup, Inge R.

1997 Incas and Spaniards in the Conquest of the Chachapoyas. GOTARC Series B. Göthenburg Archaeological Theses, No. 7. National Museum of Denmark, Göthenburg.

Steinkeller, Piotr

2003 Archival Practices at Babylonia in the Third Millennium. In Ancient Archives and Archival Traditions, edited by Maria Brosium, pp. 37-58. Oxford University Press, Oxford.

Urton, Gary

1994 A New Twist in an Old Yarn: Variation in Knot Directionality in the Inka Khipu. Baessler-Archiv Neue Folge, Band XLII:271-305.

1997 The Social Life of Numbers: A Quechua Ontology of Numbers and Philosophy of Arithmetic. University of Texas Press, Austin.

$\rightarrow 2001$ A Calendrical and Demographic Tomb Text from Northern Peru. Latin American Antiquity 12:127-147.

2002 Recording Signs in Narrative-Accounting Khipu. In Narrative Threads: Accounting and Recounting in Andean Khipu, edited by Jeffrey Quilter and Gary Urton, pp. 171-196. University of Texas Press, Austin.

2003 Signs of the Inka Khipu: Binary Coding in the Andean Knotted-String Records. University of Texas Press, Austin.

2005 Carlos Radicati di Primeglio: Patron of Peruvian Quipu Studies. An Introduction to the Re-edition of Works by C. Radicati di Primeglio. Universidad Nacional Mayor de San Marcos, Lima, in press.

Urton, Gary, and Carrie J. Brezine

2005 Information Control in the Palace of Puruchuco: An Accounting Hierarchy in a Khipu Archive from Coastal Peru. In Power in the Inka Empire, edited by Richard Burger, Ramiro Matos M., and Craig Morris. Dumbarton Oaks, Washington, D.C., in press.

von Hagen, Adriana

2000 Nueva iconografía Chachapoyas." Íconos: Revista peruana de conservación, arte y arqueología 4:8-17.

von Hagen, Adriana, and Sonia Guillén

1998 Tombs with a View. Archaeology 51(2). 2:48-54. 


\section{Notes}

1. The khipu database that we are currently developing at Harvard is a searchable database (see website at http://khipukamayuq.fas.harvard.edu/). I would note that the database created by the Aschers $(1978,1988)$, which is the most important and valuable resource to date for khipu scholars, is in PDF format and is not, therefore, searchable by electronic means. The Aschers' tables also do not include information on such khipu construction variables as directionality of cord spin/ply or directional variation in cord attachment and knotting (see Urton 2003:56-57).

2. Thanks to Gareth Cook of the Boston Globe for several additional references to matching khipu (he informed me that he had learned of them from Marcia Ascher).

3. I recently published a book outlining a binary codingbased theory on the encoding and decoding of information in the Inka khipu (Urton 2003). That theory, which I presented clearly as a hypothesis for further testing and analysis, is now in the public domain and will stand, fall, or be modified under critiques, challenges, support, etc. that it receives from other scholars, as well as appropriate testing by the Khipu Database project. The point is, the present study reflects very few of the methodological approaches and theoretical stances developed in my book on binary coding. I am emphatically not rejecting that theory, but neither do I intend to be limited to the ideas and approaches developed in that publication. Thus, in the present study, I take up another body of information and another line of approach-without prejudice to my earlier work-on the perennially difficult problem of interpreting the Inka khipu.

4. To the best of my knowledge, the first person to argue explicitly in favor of an "archival" approach to khipu studies was Radicati di Primeglio (1964:9). His study was based on six samples recovered from the Santa River Valley. Radicati di Primeglio's appeal for a study of all khipu samples from a given site, no matter how incomplete or fragmentary, was made in direct opposition to Nordenskiöld (1925). With his preoccupation for the study of astronomical and calendrical periodicities in the khipu, Nordenskiöld asserted that it made sense only to study complete khipu.

5. The Aschers' khipu tables are available online at: http://instruct1.cit.cornell.edu/research/quipu-ascher/

6. The convention in the field of khipu studies is for the first investigator of a sample to assign an investigator identification label (e.g., AS = Ascher, UR = Urton), along with a unique number for each sample. Although it is common practice to have only one reading of a khipu, and for subsequent researchers to add information to the existing description (e.g., see Urton 2003:58), the convention of assigning unique investigator labels and numbers also allows subsequent researchers to produce, and distinguish among, multiple, independent readings of samples.

7. Color abbreviations, terms, and the notation for combining colors follow the system of Marcia and Robert Ascher (1978, 1988), as explained in the introduction section of their website, http://instruct1.cit.cornell.edu/research/quipuascher/contents.htm

8. It should be noted that AS159 and 173 were each loosely tied to other khipu at the time of their study. AS159 was tied to AS160 and AS173 was tied to AS174. Sums of values on certain groups of pendants on AS173 are recorded on AS174 (see the discussion of these related khipu samples in Ascher and Ascher's Databooks [on-line resource; see above, Note 5] under AS98, Note 5). Thus, khipu AS174 may represent an additional matching-i.e., "checks and balances"- account vis-á-vis the pair AS173 and AS159.

9. Thanks to Frank Salomon, who reminded me of the valuable information on Mesopotamian accounting methods presented in the wonderful book by Nissen et al. (1993), Archaic Bookkeeping.

10. The relevant color codings for the three khipu in Figure 7 in Mackey's (1970) color nomenclature are as follows:

$$
\begin{array}{ll}
\text { Monochrome } & \text { bi-/multi-color } \\
\text { C = light brown } & 2=\text { black and white } \\
\mathrm{G}=\text { blue } & 4=\text { green and white } \\
\mathrm{B}=\text { white } & 10=\text { blue and white } \\
\mathrm{A}=\text { brown } &
\end{array}
$$

11. It is not commonly understood by those not directly involved in khipu studies that it is, in fact, often extremely difficult to read, or interpret, khipu knots. This is especially true when single knots are tied closely together on very thin cords; similarly, on loosely spun, very hairy cords, it is often virtually impossible to determine the exact number of turns in a tightly tied long knot.

12. From what I have learned from museum notes and from Dr. Sonia Guillen's (1999) salvage report on the recovery of the material from Lake of the Condors, Khipu UR6 was found in Chullpa 3 at the site of LC1 (i.e., the main rock overhang on the cliff face directly above Lake of the Condors). Khipu UR9 was also found in LCI, but within Chullpa 4. As far as I am aware, the whereabouts of the third sample, UR21, at the time of its recovery is not recorded.

13. The numerical values of knots on Khipu UR6 reported in an earlier publication (Urton 2001:141, Figure 9) contain two errors. These occur in the last pendant/loop pendant grouping (i.e., the bottom set of 21/9 cords in Year 2, Section d). The correct values should read as follows: (a) for this set of 21 pendants, the value is 12 (rather than the reported 26), and (b) for the loop pendant, the value is 37 (rather than the reported 66). The correct values are given in Table 1 (see below, in text), last two lines in Section d. These corrections change the total knot count from the 3005 , reported in 2001 , to 2962 , as reported herein. This correction will obviously affect the interpretation of the astronomical and calendrical significance of numerical values recorded on UR6 as discussed in that earlier study (Urton 2001:140-143, Table 2).

14. Thanks to R.T. Zuidema who supplied me with these references to the four-month periodicity of accounting in Inka and early colonial Cusco.

15. Marcia Ascher (2002) has discussed, in general theoretical terms, the use of khipu numerical values as labels, rather than as magnitudes.

16. In an earlier study (Urton 2002), I discussed the existence of several hundred instances of three-term "anomalous" numerical values that appear on a khipu from ChancayB/8705-in the American Museum of Natural History, in New York. It will be important in the future to analyze the relationship between the three-term number series in Chachapoyas with those on the AMNH sample from Chancay.

Submitted February 16, 2004; Accepted June 17, 2004;

Revised February 23, 2004. 